\title{
How do tree competition and stand dynamics lead to spatial patterns in monospecific mangroves?
}

\author{
M. N. I. Khan ${ }^{1,2,3,{ }^{*} \text {, S. Sharma }}{ }^{3}$, U. Berger ${ }^{2}$, N. Koedam ${ }^{4}$, F. Dahdouh-Guebas ${ }^{1,4}$, and A. Hagihara ${ }^{3}$ \\ ${ }^{1}$ Laboratory of Systems Ecology and Resource Management, Département de Biologie des Organismes, Faculté des Sciences, \\ Université Libre de Bruxelles - ULB, CP 264/1, Avenue F.D. Roosevelt 50, 1050 Brussels, Belgium \\ ${ }^{2}$ Institute of Forest Growth and Forest Computer Sciences, TU Dresden, P.O. 1117, 01735 Tharandt, Germany \\ ${ }^{3}$ Laboratory of Ecology and Systematics, Faculty of Science, University of the Ryukyus, 1 Senbaru, Nishihara-cho, \\ Okinawa 903-0213, Japan \\ ${ }^{4}$ Laboratory of Plant Biology and Nature Management, Faculty of Sciences and Bio-engineering Sciences, Vrije Universiteit \\ Brussel-VUB, Pleinlaan 2, 1050 Brussels, Belgium \\ * present address: Laboratory of Systems Ecology and Resource Management, Département de Biologie des Organismes, \\ Faculté des Sciences, Université Libre de Bruxelles - ULB, Campus de la Plaine, CP 264/1, Avenue F.D. Roosevelt 50, \\ 1050 Brussels, Belgium
}

Correspondence to: M. N. I. Khan (mkhan@ulb.ac.be, mnikhan@yahoo.com)

Received: 28 December 2012 - Published in Biogeosciences Discuss.: 31 January 2013

Revised: 8 April 2013 - Accepted: 11 April 2013 - Published: 30 April 2013

\begin{abstract}
Information on mangrove stand development is rare because long-term monitoring data is often lacking. Such information is important in order to plan management measures effectively. Novel approaches based on existing datasets are required to bridge this gap of knowledge. This study uses a unique combination of field data analyses with simulation experiments in order to demonstrate how information on mangrove dynamics can be extracted if data are sparse. The paper provides a baseline characterization of stand development in a monospecific pioneer mangrove stand of Kandelia obovata. Point pattern analyses revealed that in the young stage, self-thinning has started but has not yet lead to a regularity of spatial tree distribution in the entire stand, and trees located in smaller clumps hinder each other in growth but do not lead to a significant size class differentiation. However, after ca. 2 decades the self-thinning and the size class differentiation start to become more visible. A mutual inhibition of growth was observed within $2 \mathrm{~m}$ circular distance $(r)$ in the young stage and within $3 \mathrm{~m}$ distance after two decades of stand development as confirmed by the negative values of mark correlation function. As a stand grows older the spatial pattern of individuals become more regular from a clustered pattern. In order to understand and predict the future stand development, simulation experiments were carried out by means of the individual-based model KiWi.
\end{abstract}

\section{Introduction}

Mangroves dominate the intertidal zone of the tropical and subtropical coasts, and play a major role in the food webs and nutrient cycles, also in the adjacent marine ecosystems (Alongi et al., 2000; Machiwa and Hallberg, 2002; Mumby et al., 2004; Kristensen et al., 2008). Although the ecological and economic significance (Rönnbäck, 1999) of mangroves is highly acknowledged, the ecological processes driving their dynamics are still poorly understood (Kathiresan and Bingham, 2001; Comley and McGuinness, 2005; Khan et al., 2007; Berger et al., 2008; Cannicci et al., 2008; Krauss et al., 2008) because of the absence of long-term monitoring data. While numerous studies address the effect of abiotic conditions (Cintron et al., 1978; Ball, 1988; Clarke and Allaway, 1993) and disturbances (Piou et al., 2006) on forest dynamics, the importance of biotic interactions and their impact on the temporal, vertical and horizontal patterns of mangrove forests is still under-represented in scientific investigations (Berger and Hildenbrandt, 2000, 2003).

The spatial patterns and population structure of mangroves, however, constitute important aspects in ecosystem functions (Osunkoya and Greese, 1997; Krause et al., 2001; Ellison, 2002; Sherman et al., 2003). They are fingerprints of important key factors, such as local competition 
for photosynthetic light in the canopy (Clarke and Allaway, 1993; Khan et al., 2004), microtopography (DahdouhGuebas et al., 2007; Di Nitto et al., 2008), vegetation composition (Jayatissa et al., 2002; Kairo et al., 2002), sediment chemistry (Thiobodeau and Nickerson, 1986; Clarke and Allaway, 1993; McKee, 1995; Alongi et al., 2004), tidal elevation (Clarke and Myerscough, 1993), salinity (Clarke and Allaway, 1993; Krauss et al., 2008), dispersal patterns (Rabinowitz, 1978; Clarke and Myerscough, 1991; Clarke, 1993), and the competitive ability of species (Clarke and Myerscough, 1993; Berger and Hildenbrandt, 2000, 2003; Canham et al., 2004).

There are differences in structural patterns (e.g. tree size, species composition, soil-plant interaction, etc.) between terrestrial (Manabe et al., 2000; Hegland et al., 2001; Souza and Martins, 2004; Wilson et al., 2004; Kubota, 2006; Salas et al., 2006) and mangrove (Osunkoya and Greese, 1997; Krause et al., 2001; Kairo et al., 2002; Dahdouh-Guebas and Koedam, 2006) forest systems. Structural patterns in mangrove forests depend on the distance to the sea or proximate water channel (e.g. Osunkoya and Greese, 1997; Kairo et al., 2002), elevation (Castaneda-Moya et al., 2006) or even latitudinal gradients (DeLange and DeLange, 1994). In mangrove forests, the spatial patterns of individuals have been analysed based on the distance from the sea to the forest (Osunkoya and Greese, 1997), on soil resources regulators and the hydroperiod (Castaneda-Moya et al., 2006) or on the ecosystem level (Krause et al., 2001). However, the relationship between local competition among trees as one of the major driving factors and the resulting size and spatial distribution of individuals remains little explained. This is essential for a general understanding of mangrove forest dynamics. In order to analyse mangrove forest dynamics, it is thus critical to analyse comprehensively both the structural and spatial distribution patterns of individuals and their temporal change.

The analysis of the self-thinning process (Shinozaki and Kira, 1961; Yoda et al., 1963; Lonsdale, 1990; Osawa and Allen, 1993; Enquist et al., 1998, 1999; Hagihara, 2013) and spatial point process (Stoyan and Stoyan, 1994; Stoyan and Penttinen, 2000; Law et al., 2009) of individual trees based on a time series, for example, provides insights about the density-dependent mortality induced by local competition and its effect on the overall size of the surviving plants. In the present study, we aimed at addressing the following research questions, in particular: how are individual trees in a monospecific pioneer mangrove stand spatially distributed in the course of stand development? How does tree competition influence the demographic events, such as growth, mortality, biomass, etc. during the stand development? How do tree competition and stand dynamics lead to spatial patterns in monospecific mangroves?
Table 1. Parameters used for the simulations of the mangrove Kandelia obovata obtained according to procedure of pattern-oriented modelling (POM) (Grimm et al., 1996, 2005; Fontalvo-Herazo et al., 2011) and field data.

\begin{tabular}{llr}
\hline Parameters & Description & Value \\
\hline$a$ & Scaling factor for FON & 14.55 \\
$b$ & Scaling factor for FON & 0.914 \\
$F_{\max }$ & Maximum value of the FON & 1 \\
$F_{\min }$ & Minimum value of the FON & 0.075 \\
$G$ & Growth constant & 83.85 \\
$D_{\max }$ & Maximum dbh $(\mathrm{cm})$ & 20 \\
$H_{\max }$ & Maximum height $(\mathrm{cm})$ & 600 \\
$b_{2}$ & Constant in height to dbh relationship & 46.3 \\
$b_{3}$ & Constant in height to dbh relationship & 1.158 \\
$\Delta \mathrm{dbh}_{\text {crit }}$ & Mortality threshold & 0.191 \\
$\varphi$ & Resource sharing capacity & 1.5 \\
\hline
\end{tabular}

Note: FON-field of neighbourhood (Berger and Hildenbrandt, 2000).

\section{Materials and methods}

\subsection{Experiment setup and study site}

In order to investigate on the temporal change of structural and spatial patterns of individual trees in the mangrove stand, simulation experiments were performed using the individualbased model KiWi (Berger and Hildenbrandt, 2000), which was originally applied for a neotropical mangrove forest (Piou et al., 2006; Berger et al., 2008; Fontalvo-Herazo et al., 2011). For this purpose, at first field data were collected to parameterize the KiWi model so that the model could mimic the dynamic growth, competition and mortality in the monospecific mangrove stand of Kandelia obovata (S., L.) Yong (Table 1). The values of the model parameters were obtained according to the procedure of pattern-oriented modelling (POM) (Grimm et al., 1996, 2005; Fontalvo-Herazo et al., 2011).

Besides the KiWi, there is another model currently available to simulate long-term dynamics of mangrove development based on soil nutrient conditions and salinity: FORMAN (Chen and Twilley, 1998). The KiWi model serves as a useful tool for the studies of vegetation dynamics (Berger and Hildenbrandt, 2003; Fontalvo-Herazo et al., 2011) in mangroves, provided that the model parameters (Table 1) are tuned based on the field data obtained from those particular mangroves (Berger and Hildenbrandt, 2000; Piou et al., 2006; Berger et al., 2008). The advantage of KiWi model is that the parameters are easy to obtain even with limited availability of data. This model is spatially explicit, and it describes individual trees by their stem position, stem diameter, stem height and the so-called field of neighbourhood (FON) defining the area within which a tree influences and is influenced by its neighbours. The growth of trees depends on a tree's age, environmental conditions at 


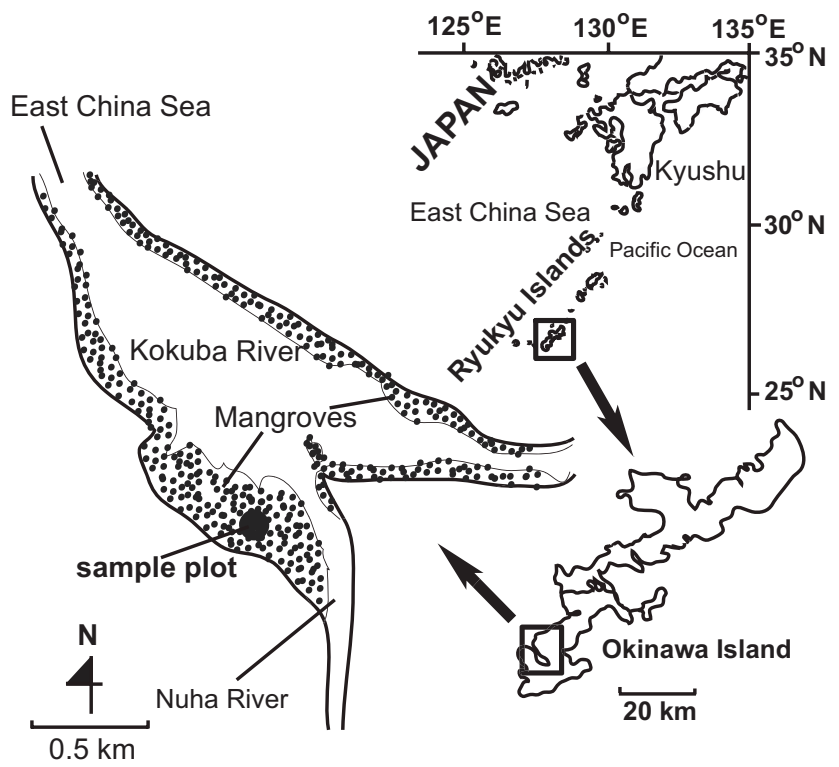

Fig. 1. Location of the study site in the Manko Mangroves, Okinawa, Japan.

stem position and neighbourhood competition. The mortality increases with growth reduction. The establishment of new saplings depends on both environmental conditions at the particular location and competition strength at this location exerted by the already established trees (described by the sum of their FONs). A detailed description of the model following the ODD (Overview, Design concepts, Details) protocol for describing the individual-based models (Grimm and Railsback, 2005; Grimm et al., 2006, 2010) is provided in Table 2.

For the purpose of field validation, the modelled results were compared with field datasets, which were collected over two decades of stand development. The study site was located in the mangroves at Manko Wetland $\left(26^{\circ} 11^{\prime} \mathrm{N}\right.$ and $127^{\circ} 40^{\prime}$ E), Okinawa Island, Japan (Fig. 1). The mangrove Kandelia obovata (S., L.) Yong has formed continuous monospecific stands in the Manko Wetland. The species $K$. obovata is considered as a pioneer species in mangrove succession. The stem diameter, height and the $x-y$ coordinates of all the trees in a $20 \times 20 \mathrm{~m}^{2}$ plot in a monospecific $K$. obovata stand were recorded at different time steps of stand development. In the study site, the mean tree height and density in the monospecific stand (ca. $12 \mathrm{yr}$ old) were recorded as ca. $4 \mathrm{~m}$ and 15450 trees ha ${ }^{-1}$, respectively. Near the study site, the mean minimum, mean maximum and mean annual temperatures were $16.8^{\circ} \mathrm{C}, 28.8^{\circ} \mathrm{C}$ and $23.2^{\circ} \mathrm{C}$, respectively. Rainfall was over $100 \mathrm{~mm} \mathrm{month}^{-1}$ throughout the year, and the mean annual rainfall was $2086 \mathrm{~mm} \mathrm{yr}^{-1}$ (Khan et al., 2004). The study plot was assumed to be equiformal (isotropic), i.e. without any effective gradient in terms of tidal inundation within the plot.

\subsection{Data analyses}

Using the field datasets, the coefficient of variation (CV \%) of tree diameter and height against the cumulative sample area was used to describe the stand structure and to investigate the existence of horizontal heterogeneity of tree sizes in the Kandelia obovata stand.

Point pattern analyses were carried out (Stoyan and Stoyan, 1994; Stoyan and Penttinen, 2000) in order to gain a deeper understanding of the ecological drivers behind the spatial patterns. The pair correlation function (PCF) $g(r)$, which is related to Ripley's $K$ function (Ripley, 1979), provides a measure of the density of neighbouring plants and gives a general notion of a "plant's eye" view (Turkington and Harper, 1979; Mahdi and Law, 1987; Law et al., 2009) of a vegetation assemblage. The PCF was used to detect uniform, clumped or random patterns in tree occurrence where trees are considered as points in a spatial point process (Stoyan and Stoyan, 1994):

$g(r)=\frac{1}{2 \pi r} \cdot \frac{\mathrm{d} K(r)}{\mathrm{d} r}$,

where $K(r)$ is the Ripley's $K$ function (Ripley, 1979) and $r$ is the particular search radius. Provided that $P(r)$ is the probability of detecting points at locations $x$ and $y$ within a distance $r$, and $\lambda$ is the intensity of the point process (Stoyan and Stoyan, 1994):

$P(r)=\lambda^{2} \cdot g(r) \cdot \mathrm{d} x \cdot \mathrm{d} y$,

where trees are completely randomly distributed (uniform Poisson process), then $p(r)=\lambda^{2}$ and $g(r)=1$. Values $g(r)<1$ suggest that the trees are more regularly distributed. Values greater than 1 suggest a clustering.

In order to detect the dynamics of intraspecific competition over stand development, a mark correlation function (MCF) $k_{\mathrm{mm}}(r)$ using dbh as marks (Stoyan and Stoyan, 1994; Getzin et al., 2008; Law et al., 2009) was used. The MCF provides the distance-dependent size correlation of trees and detects whether competition affects tree growth. The MCF quantifies the similarity and dissimilarity between dbh marks of two neighbouring trees occurring at a distance $r$ by the function $f(m 1, m 2)=m 1 \times m 2$, where $m 1$ and $m 2$ are dbh values of the two trees. The term $k_{\mathrm{mm}}(r)$ is defined as the normalized mean value of $f(m 1, m 2)$ for all marks at distance $r$. Marks are considered independent, positively or negatively correlated at distance $r$ if $k_{\mathrm{mm}}(r)=1, k_{\mathrm{mm}}(r)>1$ or $k_{\mathrm{mm}}(r)<1$, respectively. A positive mark correlation suggests a "mutual stimulation", i.e. facilitation, and a negative mark correlation suggests a "mutual inhibition". The MCF can be written in the following form:

$k_{\mathrm{mm}}(r)=\frac{E[f(m 1, m 2)]}{E\left[f\left(M, M^{\prime}\right)\right]}$,

where $r, m 1$ and $m 2$ are same as above; $M, M^{\prime}$ are random marks drawn independently from the marginal distribution of marks; and $E$ is the usual expectation. 
Table 2. Model description following the ODD protocol (Grimm and Railsback, 2005; Grimm et al., 2006, 2010).

\begin{tabular}{|c|c|}
\hline \multicolumn{2}{|l|}{ Overview } \\
\hline Purpose of the model & $\begin{array}{l}\text { The purpose of this study was to analyse the temporal change of the spatial distribution pattern of trees and stand } \\
\text { development in the monospecific mangrove K. obovata, where the trees compete with their neighbours for spatially } \\
\text { limited resources such as space and light. }\end{array}$ \\
\hline $\begin{array}{l}\text { State variables and } \\
\text { scales }\end{array}$ & $\begin{array}{l}\text { Individual trees are described primarily by their stem position, stem diameter (dbh), and age. Other descriptors such as } \\
\text { stem height or the dimension of the field-of-neighbourhood (FON), used to describe local neighbourhood competition } \\
\text { among trees, are derived from the dbh as shown in the growth function (see below). Species-dependent tree growth is } \\
\text { calculated annually. The spatial dimension and shape of the forest stand are variable. Plot sizes of the simulation area } \\
\text { of } 100 \mathrm{~m} \times 100 \mathrm{~m} \text { were used for this study. }\end{array}$ \\
\hline $\begin{array}{l}\text { Process overview } \\
\text { and scheduling }\end{array}$ & $\begin{array}{l}\text { The following processes occur each year: establishment of new saplings, growth of existing trees, and tree mortality. } \\
\text { The stem diameter of all trees is updated synchronously and the derived parameters such as tree height and FON } \\
\text { radius are re-calculated. }\end{array}$ \\
\hline \multicolumn{2}{|l|}{ Design concepts } \\
\hline Emergence & $\begin{array}{l}\text { Population dynamics emerge from the life processes modified by tree-to-tree competition, e.g. oscillation dynamics } \\
\text { of tree densities and basal areas, or variations in the spatial distributions of trees ranging from clumped to random to } \\
\text { regular, among others. }\end{array}$ \\
\hline Interactions & Trees compete for all spatially distributed resources (not explicitly specified) via their FONs. \\
\hline Sensing & Trees "sense" the distance, size and explicit location of their neighbours by their overlapping FONs. \\
\hline Stochasticity & $\begin{array}{l}\text { Saplings establish randomly, depending on local conditions. There is a random mortality in addition to the density } \\
\text { dependent mortality, which is completely deterministic. }\end{array}$ \\
\hline Observations & The model provides yearly tracking of all state variables and derived parameters for all trees. \\
\hline \multicolumn{2}{|l|}{ Details } \\
\hline Initialization & $\begin{array}{l}\text { Scenario 1: the forest area is to be colonized by trees located identically to the real plot, keeping the original tree } \\
\text { positions, original tree dbh and } 12 \mathrm{yr} \text { as starting age. Scenario } 2: \text { stand development based on random tree } \\
\text { positions, an initial height of } 1.37 \mathrm{~m} \text { and a stem dbh of } 2.5 \pm 0.25 \mathrm{~cm}, 1 \mathrm{yr} \text { as starting stand age and varying initial } \\
\text { stand densities (ca. } 5000,10000,15000 \text { and } 20000 \text { at } 12 \mathrm{yr} \text { stand age). }\end{array}$ \\
\hline Input & $\begin{array}{l}\text { Yearly recruitment rates define the establishment of new saplings. Abiotic factors such as topography, inundation } \\
\text { height, inundation frequency, pore water salinity and nutrient availability can be addressed explicitly by } \\
\text { user-supplied maps corresponding to the simulated forest stand; but for the purpose of this study they were } \\
\text { considered to be optimal for the whole forest. }\end{array}$ \\
\hline \multicolumn{2}{|l|}{ Submodels } \\
\hline $\begin{array}{l}\text { Description of a } \\
\text { single tree }\end{array}$ & $\begin{array}{l}\text { A tree is described by its } x-y \text { position, dbh, and FON. The latter describes the area within which a tree influences its } \\
\text { neighbours and is influenced by its neighbours. The radius } R \text { of the FON increases with dbh: } R=a \cdot(\mathrm{dbh} / 2)^{b} \\
\text { where } a \text { and } b \text { are species-specific scaling factors (Table 1). The intensity of FON }(r)=e^{-c(r-(d b h / 2))} \text {. }\end{array}$ \\
\hline $\begin{array}{l}\text { Recruitment and } \\
\text { establishment }\end{array}$ & $\begin{array}{l}\text { Seedling growth is not explicitly modelled due to the lack of field data. Seedling growth and mortality, however, are } \\
\text { implicitly included in the sapling recruitment rates. Saplings can establish if tree density and the resulting } \\
\text { intraspecific competition are below a certain threshold at the potential, randomly chosen location. This threshold } \\
\text { mimics a given shade tolerance of the species. }\end{array}$ \\
\hline Tree growth & $\begin{array}{l}\text { The model uses a JABOWA-type growth function, where the annual stem increment is a function of dbh and stem } \\
\text { height } H: \frac{\Delta \mathrm{dbh}}{\Delta t}=\left[\frac{G \cdot \mathrm{dbh} \cdot\left\{1-\mathrm{dbh} \cdot H /\left(\mathrm{dbh}_{\max } \cdot H_{\max }\right)\right\}}{274+3 b_{2} \cdot \mathrm{dbh}-4 b_{3} \mathrm{dbh}^{2}}\right] \cdot\left(1-\varphi \cdot C_{\mathrm{FON}}\right) \text {, with } H=137+3 b_{2} \cdot \mathrm{dbh}-4 b_{3} \mathrm{dbh}^{2} . \\
\text { This function is parameterized for optimal growth conditions. The growth multiplier }\left(1-\varphi \cdot C_{\mathrm{FON}}\right) \text { corrects the stem } \\
\text { increment depending on tree neighbourhood competition, where } \varphi \text { represents the resource sharing capacity and } C_{\mathrm{FON}} \\
\text { represents the FON intensity in each individual tree. The growth multiplier stands at one for no neighbouring trees. }\end{array}$ \\
\hline Competition & $\begin{array}{l}\text { The intensity of the FONs of all neighbouring trees on the FON of a focal tree is taken as a measure of the } \\
\text { competition strength the focal tree suffers. This value is related to the area of the FON of the focal tree, assuming } \\
\text { that the influence of larger trees on smaller ones is stronger than vice versa. }\end{array}$ \\
\hline Mortality & $\begin{array}{l}\text { The model considers mortality due to a prolonged period of growth depression. Since there is no field data available on } \\
\text { that process, the model describes it phenomenologically. A tree dies if its mean stem increment over a specified time } \\
\text { range (here } 5 \text { yr) is less than half of the average increment under optimal conditions. This occurs when the stem } \\
\text { diameter approaches its maximum, or results from salinity stress, nutrient limitation, or competition among } \\
\text { neighbouring trees. This procedure assures that a tree has a chance to recover when conditions improve, e.g. when a } \\
\text { neighbouring tree dies. }\end{array}$ \\
\hline
\end{tabular}


Self-thinning refers to the time trajectory of mean phytomass $w$ and density $\rho$ of any specific population over time, and when density-dependent mortality is occurring (Yoda et al., 1963; Enquist et al., 1998, 1999). The time trajectory of $w$ approaches a line of constant slope with respect to $\rho$ along with the progress of growth and mortality. The relationship between $w$ and $\rho$ is given as

$w=c \rho^{-\alpha}$.

In the linearized form

$\ln w=\ln c-\alpha \cdot \ln \rho$,

where $\alpha$ specifies the slope of the self-thinning line, and $\ln c$ the intercept with the vertical axis. The value of the intercept depends on the species and units of measurement (Yoda et al., 1963; Enquist et al., 1998, 1999; Silvertown and Charlesworth, 2001; Berger and Hildenbrandt, 2003). Based on different initial densities and the relationships of $w$ at different stand ages to the corresponding $\rho$ in the whole plot, the time trajectory (Ogawa, 2001; Ogawa and Hagihara, 2003; Ogawa, 2005) of $w$ and $\rho$ was approximated as

$w=K \rho^{-\alpha}\left(1-\rho / \rho_{0}\right)^{b}$,

where $K$ and $a$ represent $c$ and $\alpha$, respectively, in Eq. (4), $\rho_{0}$ specifies the initial density and $b$ is a constant.

The individual tree weight was approximated using the allometric relationships which were established for the same stand as reported in a previous study (Khan et al., 2005). All data analyses were performed using $\mathrm{R}$ software version 2.15.2 (R Development Core Team, 2011); the point pattern analysis (pair correlation and mark correlation), in particular, was performed using the "spatstat" package of R (Baddeley and Turner, 2005).

\subsection{Sensitivity analysis}

Sensitivity analysis was performed using the extended Fourier amplitude sensitivity test (eFAST), a variance-based global sensitivity method (Cukier et al., 1978; Saltelli et al., 1999, 2000) for tracing the contribution of model parameters and of the corresponding processes in individual tree size. The eFAST is model-independent and is applicable irrespective of the degree of linearity or additivity of the model. The method quantifies the contribution of the individual input parameters to the variance of the output variables. It reveals both parameter main effects on the model output and the sum of the effects due to its higher-order interactions with other parameters (Saltelli et al., 2000; Saloranta and Andersen, 2007). At first, the model parameters were obtained (Table 1) according to procedure of pattern-oriented modelling (POM) (Grimm et al., 1996, 2005; Fontalvo-Herazo et al., 2011). Then following the specific sampling procedure of the SimLab software package (SimLab, 2011), different parameter sets were calculated with $-10 \%$ to $+10 \%$ ranges in each

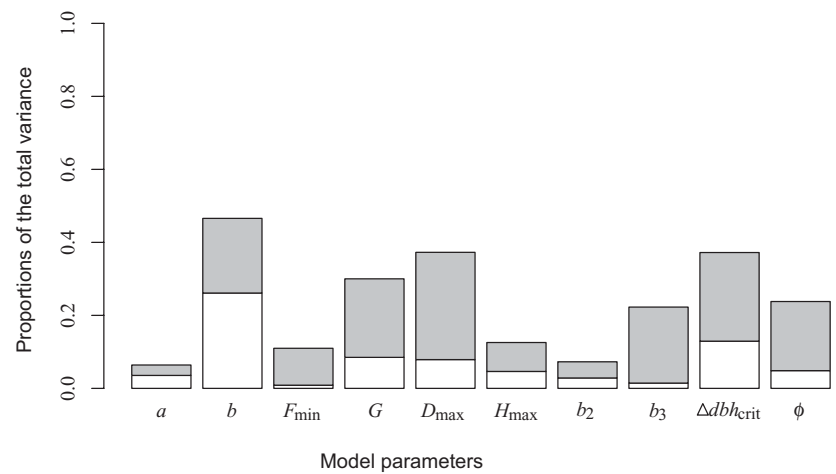

Fig. 2. Proportions of the total variance explained by model parameters (Table 1) with regard to the model output (mean tree weight at stand age $20 \mathrm{yr}$ ) analysed by the extended Fourier amplitude sensitivity test (eFAST) method. The white area (main effect) denotes the portion of total variance explained by the particular parameter alone, and the grey area (interactions) similarly the part explained by all parameter interactions where the particular parameter is included.

parameter described in Table 1 (except $F_{\max }$, which is constant for all the simulations). Next, the parameter sets were used for multiple simulation runs $(65 \times 10$ parameters $=650$ simulations) and the model output (mean tree weight at time step 20) in each simulation was recorded. Finally, the input parameter sets (total 650) and the corresponding model output were used to perform the eFAST sensitivity analysis (Fig. 2) using the "sensitivity" package (Pujol et al., 2012) in R (R Development Core Team, 2011).

\section{Results}

\subsection{Stand structure}

The coefficient of variation (CV\%) of tree diameter and height (field data) was plotted against the cumulative sample area (Fig. 3). It was observed that the $\mathrm{CV}$ of both height and diameter increases with increasing cumulative sample area, but after $200 \mathrm{~m}^{2}$ area the $\mathrm{CV}$ is not influenced by the increasing sample area. This suggests the existence of little horizontal heterogeneity of tree size in the Kandelia obovata stand.

\subsection{Modelling stand dynamics}

The eFAST sensitivity analysis (Fig. 2) suggested that of the model parameters (Table 1) used in the simulation experiments, $b$ is the most influential followed by the mortality parameter $\Delta \mathrm{dbh}_{\text {crit }}$ and the growth parameter $G$. The parameter $b$ specifies the field of neighbourhood (FON) intensity (Table 2) depending on $\mathrm{dbh}$, and $G$ influences the annual dbh increment. This reveals that in KiWi the tree size (through FON intensity) and growth rate influence the competition strength 


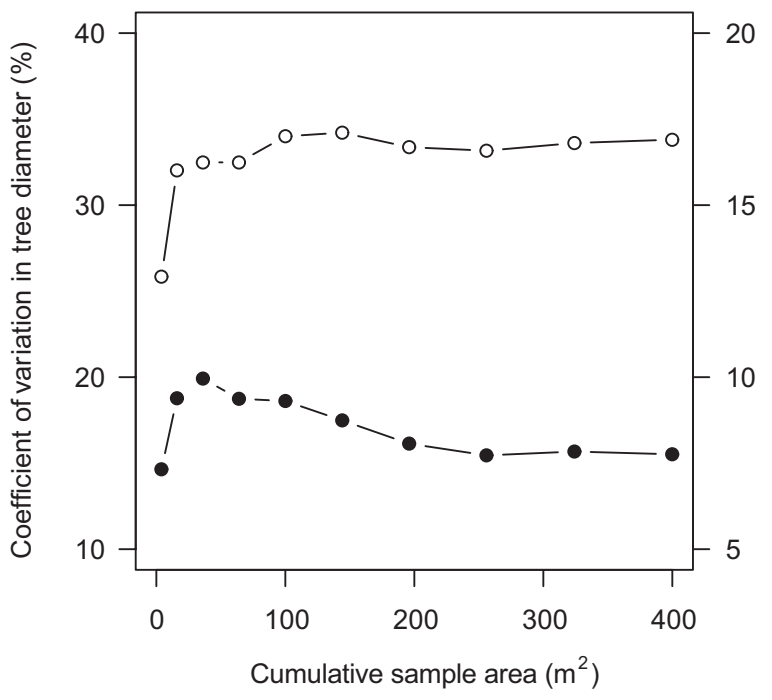

Fig. 3. Relationships of coefficient of variation of tree diameter and height to cumulative sample area in the Kandelia obovata sample plot (o diameter, $\bullet$ height)

in individual trees, and that the probability of death of an individual tree depends on its growth performance.

In the simulation experiments with an initialization (Scenario 1, Table 2) of forest area by trees located identically to the original tree positions, original tree $\mathrm{dbh}$ and $12 \mathrm{yr}$ as starting age, it was evident that the time trajectory of mean tree weight $w$ and density $\rho$ (Fig. 4) in the Kandelia obovata stand follows the self-thinning line in the course of stand development. The simulated values of dynamic mean tree weight showed strong similarity to that of field data, suggesting the robustness of the KiWi model for predicting the dynamics in stand development of the mangrove $K$. obovata. Likewise, the relationships of pair correlation function $g(r)$ to distance $r$ at different stand ages using the simulated and field datasets showed strong similarities (Fig. 5). In the young stage (12 yr old), $g(r)$ shows large values ( $>1$ ") for search radii smaller than $50 \mathrm{~cm}$, verifying the clumping of trees in short distances (Fig. 5). The curve dropping below "1" for distances between $50 \mathrm{~cm}$ and $150 \mathrm{~cm}$ shows that trees tend to occur slightly regularly within these distances irrespective of age and dbh. However, $g(r)$ specifies overall spatial randomness in tree locations for larger distances. After the stand age reaches $20 \mathrm{yr}$ (Fig. 5), $g(r)$ shows changes from clumping to slight regularity for search radii smaller than $50 \mathrm{~cm}$, and this trend continues up to a distance of $2 \mathrm{~m}$. As stand growth proceeds, the $g(r)$ values for search radii of $<2 \mathrm{~m}$ indicated that the spatial pattern of trees changes from clumped to more uniform distribution (Fig. 5).

In the young stage (12 yr old), the mark correlation function $k_{\mathrm{mm}}(r)$ confirmed the existence of intraspecific competition in the stand (Fig. 6) as indicated by the curve dropping below "1" (negative mark correlation) for distances up

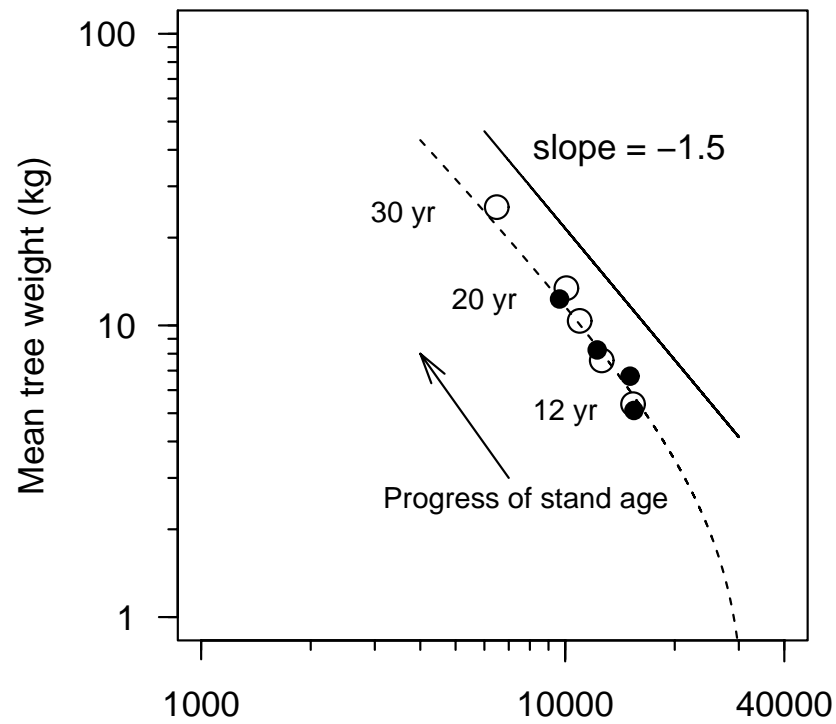

Tree density $\left(\mathrm{ha}^{-1}\right)$

Fig. 4. Time trajectory of mean tree weight $(\mathrm{kg})$ in Kandelia obovata in relation to stand development (• observed, o simulated). The curve represents the Eq. (6) fitted $\left(R^{2}=0.967\right)$ on the observed dataset, where the coefficients are $K=2.202 \times 10^{6}, a=1.299$, $\rho_{0}=3.164 \times 10^{4}$ and $b=0.503$. The straight line indicates the socalled self-thinning line.

to $2 \mathrm{~m}$. This suggests that neighbouring trees within $2 \mathrm{~m}$ distance are dissimilar in size (dbh), confirming a growth inhibition among the neighbours, and large trees (similar in size) maintain a distance among themselves. This inhibition distance reached up to $3 \mathrm{~m}$ after two decades of stand development (Fig. 6). The size distribution of mortality of trees confirmed that the smaller sized trees are more prone to die (Fig. 7), triggering the regularity of spatial pattern over stand development. The phenomenon of clumping in short distances (Fig. 5) in young stage (observed data) and the spatial randomness in larger distances (observed and simulated data) are in agreement with the dynamics of tree size distribution indicating the high proportion of mortality in smaller trees. The mortality process in relation to stand density is further clarified by the simulation experiments with an initialization (Scenario 2, Table 2) of forest area by trees located on random initial tree positions, an initial height of $1.37 \mathrm{~m}$ and a stem dbh of $2.5 \pm 0.25 \mathrm{~cm}, 1 \mathrm{yr}$ as starting age and varying stand densities. It was confirmed that the higher the initial stand density, the higher the rate of mortality and the quicker the stand reaches the so-called self-thinning line (Fig. 8).

\section{Discussion}

This study focused on a comprehensive analysis of the early stage of stand development processes in the monospecific Kandelia obovata mangrove forest. Simulation experiments, 


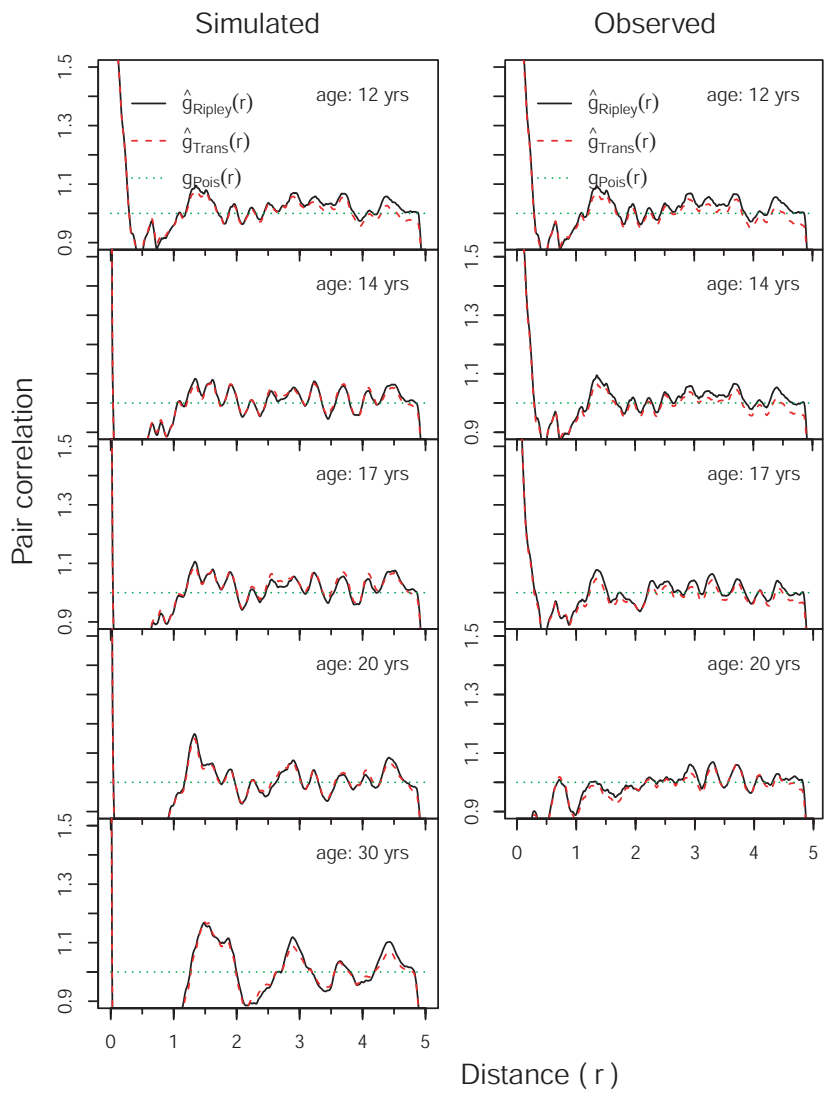

Fig. 5. Relationships of pair correlation function $g(r)$ to distance $r$ at different stand age in the Kandelia obovata stand initiated with existing density and based on tree positions obtained from field data. The solid lines indicate isotropic-corrected estimate of $g(r)$, the dashed lines indicate translation-corrected estimate of $g(r)$ and the dotted lines indicate Poisson's expectation.

starting with the present configuration of the study sites, provided a forecast of the stand development to be expected in the future. The combined analysis of empirical and simulated data was useful for both finding the baseline for stand development and producing a time series usually not available for mangrove forests, because of the absence of long-term monitoring data.

Although the modelled results of this study were validated based on a $400 \mathrm{~m}^{2}$ plot, which seems to be a small sample plot for a vegetation study, it was observed (Fig. 3) that after $200 \mathrm{~m}^{2}$ cumulative area, the coefficient of variation (CV \%) of tree diameter and height is not influenced by the increasing cumulative sample area, indicating the existence of less horizontal heterogeneity of tree sizes in the stand for a sample area larger than $200 \mathrm{~m}^{2}$. Thus, the sample plot is considered as a suitable representative of the model based on changes of the CV of tree diameter and height in relation to the cumulative sample area (Thompson, 1992). Considering the horizontal heterogeneity of tree sizes, larger sample plots would

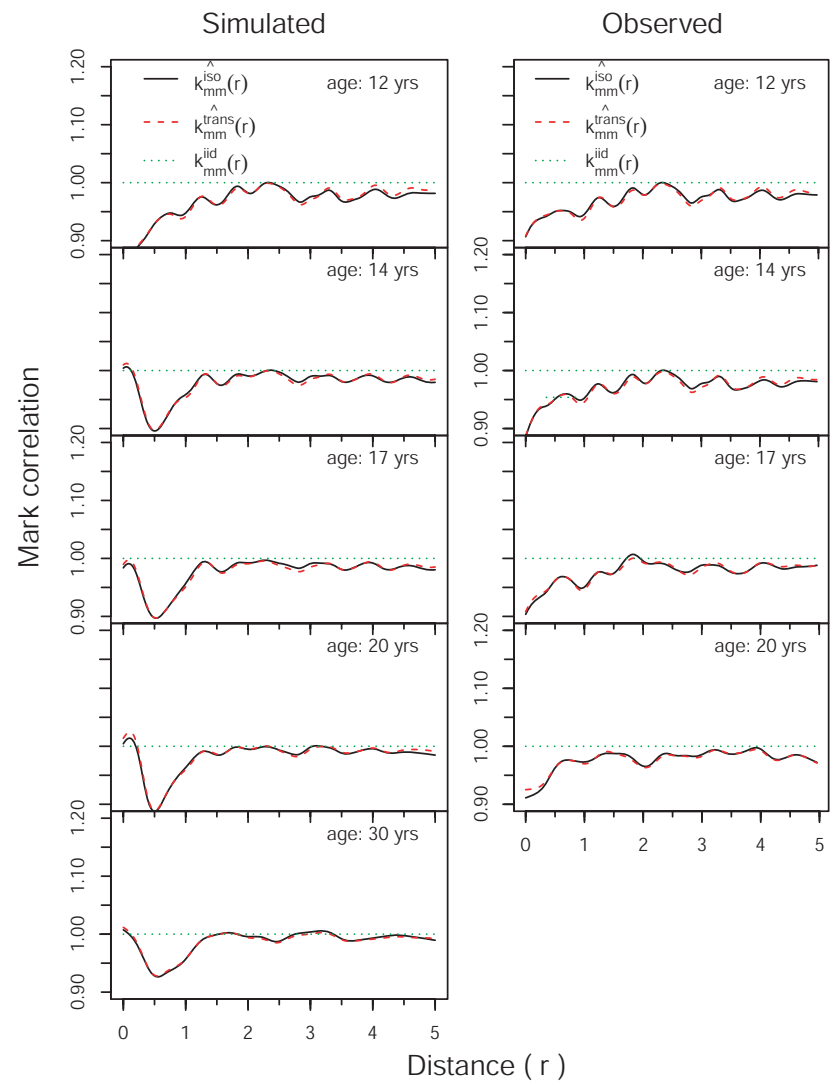

Fig. 6. Relationships of mark correlation function $k_{\mathrm{mm}}(r)$ to distance $r$ at different stand age in the Kandelia obovata stand initiated with existing density and based on tree positions obtained from field data. The solid lines indicate isotropic-corrected estimate of $k_{\mathrm{mm}}(r)$, the dashed lines indicate translation-corrected estimate of $k_{\mathrm{mm}}(r)$ and the dotted lines indicate Poisson's expectation.

not change the overall stand structure (if the site quality is assumed to be unchanged).

For simulation experiments, the KiWi model was chosen as a suitable tool for our research question. The model uses a simple but well-established growth equation (Shugart, 1984), which was originally developed for the first generation of forest simulation models. This growth equation is not as flexible as that of Asaeda and Kalibbala (2009), which describes relevant processes (e.g. photosynthesis and respiration) in detail. However, the main advantage of Shugart's function is that the parameterization is possible with the few data available for our study site as for most mangroves. It is for this reason that most of the mangrove forest simulators use this growth function (Berger et al., 2008 and citations within). Another advantage of the KiWi model is the spatially explicit description of the trees. This provides the consideration of forest inventory data by means of point pattern statistics being suitable to reveal essential ecological mechanisms and key factors beyond forest dynamics. Non-spatial mangrove models, such as the one introduced by Asaeda and Kalibbala 


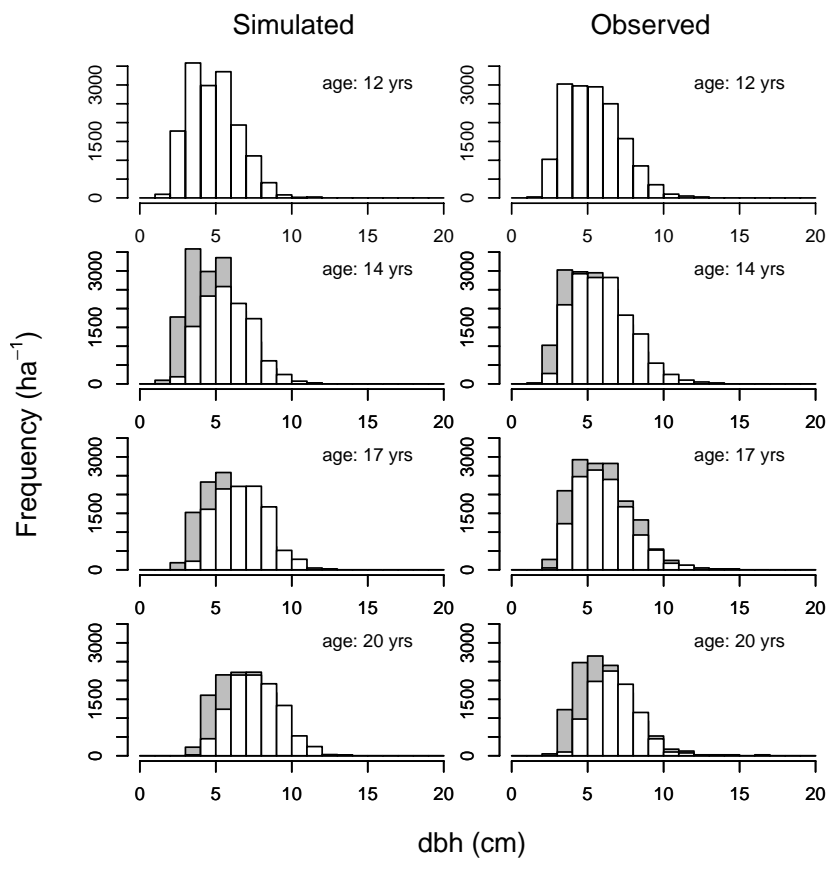

Fig. 7. Frequency distribution of tree dbh along with the mortality distribution in relation to stand development. Shaded bars indicate dead trees (with respect to previous census) and white bars indicate live trees.

(2009), are very suitable for describing stand parameters on higher hierarchical levels of the ecosystem (e.g. yield) but are not appropriate for the analysis, description and prediction of dynamic spatial patterns we are focusing on in the frame of this study. The parameters used for the experiments were tuned based on field experience, as well as results of previous reports (Khan et al., 2004, 2005, 2007, 2009) on the same study sites, where the simulated results were validated with real field data, for instance stand biomass production (Khan et al., 2009).

The mean tree weight (Fig. 4) and frequency distribution of dbh (Fig. 7) in simulated trees (Initialization: Scenario 1, Table 2) corresponded well to the observed datasets. This is a sign of validity of simulated results with observed data (see also Khan et al., 2009). The data points as time series of two decades reveal that density-dependent mortality already occurs and the self-thinning process has started. As shown in Fig. 8, the tree growth rate in independent populations having a low stand density is high, even if the populations are of the same age. If the tree growth is limited by resource availability, individuals are forced to compensate for their size, which in turn results in the mortality of some individuals. This effect is popularly known as the competition-density $(C-D)$ effect in non-self-thinning populations (Shinozaki and Kira, 1956; Silvertown and Doust, 1993; Xue and Hagihara, 2002, 2008; Hagihara, 2013). In the time trajectory, the slope $a$ (i.e. $\alpha$ in the self-thinning line) values in the curves (Fig. 4, dashed line) were estimated as -1.299 , which is not as steep

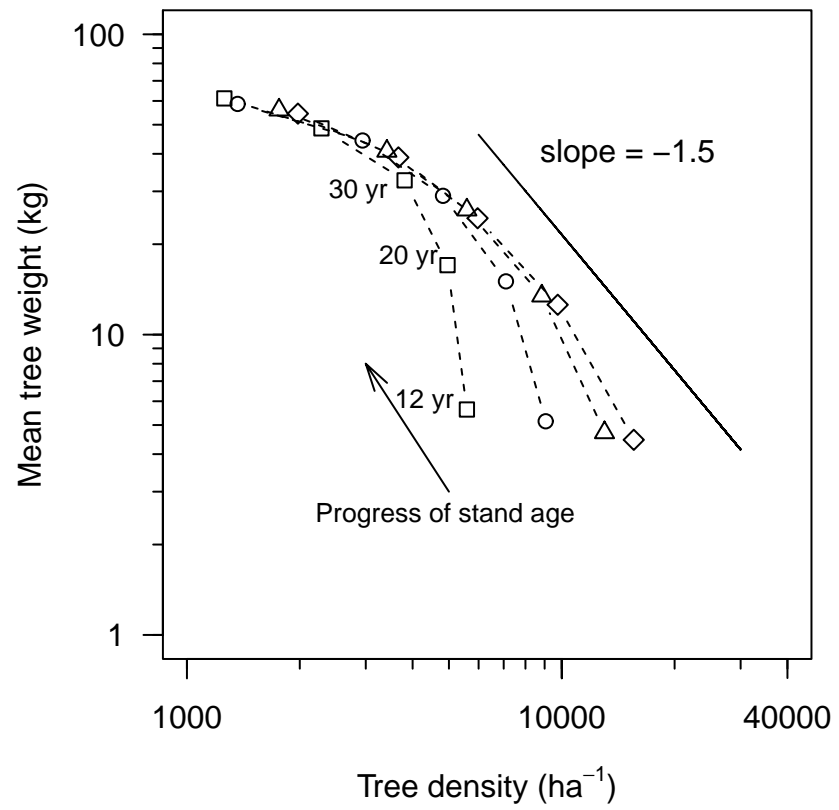

Fig. 8. Relationships of mean tree weight $(\mathrm{kg})$ to tree density $\left(\mathrm{ha}^{-1}\right)$ in relation to stand development. The arrow indicates the progress of time during stand development based on different initial densities $\left(\square 5000, \bigcirc 10000, \triangle 15000, \diamond 20000\right.$ trees ha $\left.^{-1}\right)$. The straight line indicates the so-called self-thinning line.

as the so-called self-thinning slope: -1.5 (i.e. $-3 / 2$ ). This is, however, very close to -1.333 (i.e. $-4 / 3$ ) as suggested by some investigators (e.g. Lonsdale, 1990; Osawa and Allen, 1993; Enquist et al., 1998, 1999). In agreement with Zeide (1985), Weller (1987), and Berger and Hildenbrandt (2003), however, no particular slope value is claimed. The pattern of density-dependent mortality (Fig. 7) suggests a higher mortality of smaller trees in older stands due to intraspecific competition (Xue et al., 1999; Ogawa and Hagihara, 2003), which is supported by the earlier findings that $K$. obovata is intolerant to shade (Khan et al., 2004), and the trees strongly compete for light as is true for other heliophytes (Tüffers et al., 1999; Ball et al., 1988). In the case of a closed-canopy stand when larger trees obstruct light to smaller ones, the smaller trees are thinned out because of the shade of larger ones resulting in low photosynthetic production in the former, which still have a respiration cost (Weiner and Whigham, 1988; Suwa et al., 2006).

The point pattern analysis of the spatial distribution of trees provides new insights into the study of mangrove stand development, which had not been carried out up to now. The pair correlation function (Fig. 5) gives precise information of a differentiation below the smallest diagonal distance of the smallest observation quadrat, providing the estimation with continuously increasing distances $(r)$. For this reason, it was possible to identify the scale of clumping $<50 \mathrm{~cm}$ in young stage (12 yr old), and a more regular distribution of the trees in distances between 50 and $150 \mathrm{~cm}$ in the early stages of 
growth (Fig. 6). The causes of the clumping process can be manifold, ranging from heterogeneities in seed availability due to stochasticity in seed dispersal to heterogeneities in micro-environmental conditions influencing the growth and survival of the plants (Clarke and Allaway, 1993; Frelich et al., 1993; Osunkoya and Greese, 1997; Yamada and Suzuki, 1997; Dahdouh-Guebas et al., 2007; Krauss et al., 2008). The regularity among the individuals, as indicated by the dropping of $g(r)$ values below " 1 " along with the increasing stand ages, reflects the intraspecific competition in the monospecific stand. When a short search radius is concerned, after the stand grows older the disappearance of clumping and the change of the spatial pattern of trees to more regularity indicates the existence of intraspecific competition resulting in a density-dependent mortality. The intraspecific competition and the density-dependent mortality would cause the spatial pattern of individuals to become more regular over stand development. The negative spatial association between trees of different sizes (mutual inhibition of growth), as indicated by the negative values of $k_{\mathrm{mm}}(r)$ within $2 \mathrm{~m}$ distance during the early stage and within $3 \mathrm{~m}$ distance after two decades of stand development, is an indication that small trees are associated with large neighbouring trees if competition suppresses growth (Law et al., 2009). The overall spatial randomness in tree locations for larger distances $(>2 \mathrm{~m}$ in young stage and $>3 \mathrm{~m}$ after two decades) might be related to a smaller tree crown in the K. obovata as a light-loving species (Khan et al., 2004; Suwa et al., 2006) and dwarf mangrove type (Lee, 1989), and the trees are not large enough to pose any shading threat to neighbours at large distances.

In conclusion, this study is based on a combination of empirical and simulated data describing the early stage of mangrove stand development. Simulation experiments used the current constellation of the empirical plots as the initial configuration, providing a forecast of future stand development. The experiments were carried out by means of the mangrove forest simulator KiWi, being the first individualbased model parameterized to South-east Asian mangroves. This study provides insights on spatial patterns of individual trees along with the stand dynamics: in young stage smaller clumps have been detected and self-thinning has started but has not yet lead to a regularity of spatial tree distribution in the entire stand; trees located in smaller clumps hinder each other in growth but do not lead to a significant size class differentiation; after ca. 2 decades the self-thinning and the size class differentiation start to become visible; as stand grows older the spatial pattern of individuals becomes more regular from a clustered pattern; and the mutual inhibition of growth and the resultant mortality of smaller size class would cause the change of the spatial pattern. Although this study represents a constrained species-specific model (every important point that is specific for this model as compared to a more generic mangrove) towards understanding the dynamics of spatial distribution of individual trees along with stand development, we hope that it will stimulate further research in this direction. In this work, we described the changes in spatial patterns in light of competition. However, other driving forces, such as environmental factors or dispersal pattern may also show profound influence on the changes in tree spatial patterns.

Acknowledgements. We are grateful to L. Alhamd and S. M. Feroz who provided invaluable assistance during data collection. We thank Juliane Vogt for her assistance with the parameterization of the KiWi model for the simulation experiments. We also thank the Ministry of Environment, Japan, for access to the wildlife sanctuary, and the Tomigusuku Community for permitting us to use their land. This study was partially supported by a Grant-in-Aid for Scientific Research from the Ministry of Education, Culture, Sports, Science, and Technology, Japan (nos. 16201009 and 16651009), and by the 21st Century COE program - University of the Ryukyus, Japan. The simulation experiments and data analysis performed in the Institute of Forest Growth and Forest Computer Sciences, Technische Universität Dresden (Germany) were supported by the Alexander von Humboldt Foundation, Germany. The study was completed after combing additional field data and simulation experiments as part of the project "Ecological functionality and stability of mangrove ecosystems: a modeling approach" under the grant type "Mandat d'Impulsion Scientifique" (MIS ID 1765914) of the National Science Foundation (FNRS), Belgium. We also would like to thank the anonymous reviewers for their valuable comments to improve the manuscript. This paper was presented at the conference MMM3: Meeting on Mangrove ecology, functioning and Management, Galle, Sri Lanka, 2-6 July 2012.

Edited by: S. Behara

\section{References}

Alongi, D. M., Tirendi, F., and Clough, B. F.: Below-ground decomposition of organic matter in forests of the mangroves, Rhizophora stylosa and Avicennia marina, along the arid coast of Western Australia, Aquat. Bot., 68, 97-122, doi:10.1016/S03043770(00)00110-8, 2000.

Alongi, D. M., Sasekumar, A., Chong, V. C., Pfitzner, J., Trott, L. A., Tirendi, F., Dixon, P., and Brunskill, G. J.: Sediment accumulation and organic material flux in a managed mangrove ecosystem: estimates of land-ocean-atmosphere exchange in peninsular Malaysia, Mar. Geol., 208, 383-402, doi:10.1016/j.bbr.2011.03.031, 2004.

Asaeda, T. and Kalibbala, M.: Modelling growth and primary production of the marine mangrove (Rhizophora apiculata BL): A dynamic approach, J. Exp. Mar. Biol. Ecol., 371, 103-111, doi:10.1016/j.jembe.2009.01.009, 2009.

Baddeley, A. and Turner, R.: Spatstat: an R package for analyzing spatial point patterns, J. Stat. Softw., 12, 1-42, 2005.

Ball, M. C.: Salinity tolerance in the mangroves Aegiceras corniculatum and Avicennia marina. I. Water use in relation to growth, carbon partitioning, and salt balance, Aust. J. Plant Physiol., 15, 447-464, 1988.

Ball, M. C., Cowan, I. R., and Farquhar, G. D.: Maintenance of leaf temperature and the optimisation of carbon gain in relation to 
water loss in a tropical mangrove forest, Aust. J. Plant Physiol., 15, 263-276, doi:10.1071/PP9880263, 1988.

Berger, U. and Hildenbrandt, H.: A new approach to spatially explicit modelling of forest dynamics: spacing, ageing and neighbourhood competition of mangrove trees, Ecol. Model., 132, 287-302, doi:10.1016/S0304-3800(00)00298-2, 2000.

Berger, U. and Hildenbrandt, H.: The strength of competition among individual trees and the biomass-density trajectories of the cohort, Plant Ecol., 167, 89-96, doi:10.1023/A:1023965512755, 2003.

Berger, U., Rivera-Monroy, V. H., Doyle, T. W., Dahdouh-Guebas, F., Duke, N. C., Fontalvo-Herazo, M. L., Hildenbrandt, H., Koedam, N., Mehlig, U., Piou, C., and Twilley, R. R.: Advances and limitations of individual-based models to analyze and predict dynamics of mangrove forests: a review, Aquat. Bot., 89, 260-274, doi:10.1016/j.aquabot.2007.12.015, 2008.

Canham, C. D., LePage, P. T., and Coates, K. D.: A neighborhood analysis of canopy tree competition: effects of shading versus crowding, Can. J. Forest Res., 34, 778-787, doi:10.1139/X03232, 2004.

Cannicci, S., Burrows, D., Fratini, S., Lee, S. Y., Smith III, T. J., Offenberg, J., and Dahdouh-Guebas, F.: Faunal impact on vegetation structure and ecosystem function in mangrove forests: a review, Aquat. Bot., 89, 186-200, doi:10.1016/j.aquabot.2008.01.009, 2008.

Castaneda-Moya, E., Rivera-Monroy, V. H., and Twilley, R. R.: Mangrove zonation in the dry life zone of the Gulf of Fonseca, Honduras, Estuar. Coasts, 29, 751-764, doi:10.1007/BF02786526, 2006.

Chen, R. and Twilley, R. R.: A gap dynamic model of mangrove forest development along gradients of soil salinity and nutrient resources, J. Ecol., 86, 37-51, doi:10.1046/j.13652745.1998.00233.x, 1998.

Cintron, G., Lugo, A. E., Pool, D. J., and Morris, G.: Mangroves of arid environment in Puerto Rico and adjacent islands, Biotropica, 10, 110-121, 1978.

Clarke, P. J.: Dispersal of grey mangrove (Avicennia marina) propagules in south eastern Australia, Aquat. Bot., 45, 195-204, doi:10.1016/0304-3770(93)90021-N, 1993.

Clarke, P. J. and Allaway, W. G.: The regeneration niche of grey mangrove (Avicennia marina): effects of salinity, light and sediment factors on establishment, growth and survival in the field, Oecologia, 93, 548-556, doi:10.1007/BF00328964, 1993.

Clarke, P. J. and Myerscough, P. J.: Buoyancy of Avicennia marina propagules in south-eastern Australia, Aust. J. Bot., 39, 77-83, doi:10.1071/BT9910077, 1991.

Clarke, P. J. and Myerscough, P. J.: The intertidal distribution of the grey mangrove (Avicennia marina) in southeastern Australia: the effects of physical conditions, interspecific competition and predation on propagule establishment and survival, Aust. J. Ecol., 18, 307-315, doi:10.1111/j.1442-9993.1993.tb00458.x, 1993.

Comley, B. W. T. and McGuinness, K. A.: Above- and belowground biomass, and allometry, of four common northern Australian mangroves, Aust. J. Bot., 53, 431-436, doi:10.1071/BT04162, 2005.

Cukier, R. I., Levine, H. B., and Shuler, K. E.: Nonlinear sensitivity analysis of multi-parameter model systems, J. Comput. Phys., 26, 1-42, doi:/10.1016/0021-9991(78)90097-9, 1978.
Dahdouh-Guebas, F. and Koedam, N.: Empirical estimate of the reliability of the use of the Point-Centred Quarter Method (PCQM): Solutions to ambiguous field situations and description of the PCQM+ protocol, Forest Ecol. Manag., 228, 1-18, doi:10.1016/j.foreco.2005.10.076, 2006.

Dahdouh-Guebas, F., Kairo, J. G., De Bondt, R., and Koedam, N.: Pneumatophore height and density in relation to microtopography in the grey mangrove Avicennia marina, Belg. J. Bot., 140, 213-221, 2007.

DeLange, W. P. and DeLange, P. J.: An appraisal of factors controlling the latitudinal distribution of mangrove (Avicennia marina var. resinifera) in New Zealand, J. Coastal Res., 10, 539-548, 1994.

Di Nitto, D., Dahdouh-Guebas, F., Kairo, J. G., Decleir, H., and Koedam, N.: Digital terrain modelling to investigate the effects of sea level rise on mangrove propagule establishment, Mar. Ecol.Prog. Ser., 356, 175-188, doi:10.3354/meps07228, 2008.

Ellison, A. M.: Macroecology of mangroves: large-scale patterns and processes in tropical coastal forests, Trees, 16, 181-194, doi:10.1007/s00468-001-0133-7, 2002.

Enquist, B. J., Brown, J. H., and West, G. B.: Allometric scaling of plant energetics and population density, Nature, 395, 163-165, doi:10.1038/25977, 1998.

Enquist, B. J., West, G. B., Charnov, E. L., and Brown, J. H.: Allometric scaling of production and life-history variation in vascular plants, Nature, 401, 907-911, doi:10.1038/44819, 1999.

Fontalvo-Herazo, M. L., Piou, C., Vogt, J., Saint-Paul, U., and Berger, U.: Simulating harvesting scenarios towards the sustainable use of mangrove forest plantations, Wetl. Ecol. Manag., 19, 397-407, doi:10.1007/s11273-011-9224-4, 2011.

Frelich, L. E., Calcote, R. R., Davis, M. B., and Pastor, J.: Patch formation and maintenance in an old-growth hemlock-hardwood forest, Ecology, 74, 513-527, doi:10.2307/1939312, 1993.

Getzin, S., Wiegand, K., Schumacher, J. and Gougeon, F. A.: Scale-dependent competition at the stand level assessed from crown areas, For. Ecol. Manage., 255, 2478-2485, doi:10.1016/j.foreco.2008.01.007, 2008.

Grimm, V. and Railsback, S. F. (Eds.): Individual-based Modelling and Ecology, Princeton Series in Theorical and Computational Biology, Princeton University Press, 2005.

Grimm, V., Franka, K., Jeltsch, F., Brandla, R., Uchmariskib, J. and Wissela, C.: Pattern-oriented modelling in population ecology, The Science of the total environment, 183, 151-166, doi:10.1016/0048-9697(95)04966-5, 1996.

Grimm, V., Revilla, E., Berger, U., Jeltsch, F., Mooij, W. M., Railsback, S. F., Thulke, H.-H., Weiner, J., Wiegand, T. and DeAngelis, D. L.: Pattern-oriented modeling of agent-based complex systems: lessons from ecology., Science, 310, 987-91, doi:10.1126/science.1116681, 2005.

Grimm, V., Berger, U., Bastiansen, F., Eliassen, S., Ginot, V., Giske, J., Goss-Custard, J., Grand, T., Heinz, S. K, Huse, G., Huth, A., Jepsen, J. U., Jørgensen, C., Mooij, W. M., Müller, B., Péer, G., Piou, C., Railsback, S. F., Robbins, A. M., Robbins, M. M., Rossmanith, E., Rüger, N., Strand, E., Souissi, S., Stillman, R. A., Vabø, R., Visser, U., and DeAngelis, D. L.: A standard protocol for describing individual-based and agent-based models, Ecol. Model., 198, 115-126, doi:10.1016/j.ecolmodel.2006.04.023, 2006. 
Grimm, V., Berger, U., DeAngelis, D. L., Polhill, J. G., Giske, J., and Railsback, S. F.: The ODD protocol: a review and first update, Ecol. Model., 221, 2760-2768, doi:10.1016/j.ecolmodel.2010.08.019, 2010.

Hagihara, A.: Deriving the mean mass-density trajectory by reconciling the competition-density effect law with the self-thinning law in even-aged pure stands, J. Forest Res.-Jpn., in press, doi:10.1007/s10310-013-0393-2, 2013.

Hegland, S. J., van Leeuwen, M., and Oostermeijer, J. G. B.: Population structure of Salvia pratensis in relation to vegetation and management of Dutch dry floodplain grasslands, J. Appl. Ecol., 38, 1277-1289, 2001.

Jayatissa, L. P., Dahdouh-Guebas, F., and Koedam, N.: A review of the floral composition and distribution of mangroves in Sri Lanka, Bot. J. Linn. Soc., 138, 29-43, 2002.

Kairo, J. G., Dahdouh-Guebas, F., Gwada, P. O., Ochieng, C., and Koedam, N.: Regeneration status of Mangrove forests in Mida Creek, Kenya: a compromised or secured future?, Ambio, 31, 562-568, doi:10.1579/0044-7447-31.7.562, 2002.

Kathiresan, K. and Bingham, B. L.: Biology of mangroves and mangrove ecosystems, Adv. Mar. Biol., 40, 81-251, doi:10.1016/S0065-2881(01)40003-4, 2001.

Khan, M. N. I., Suwa, R., Hagihara, A., and Ogawa, K.: Interception of photosynthetic photon flux density in a mangrove stand of Kandelia candel (L.) Druce, J. For. Res.-Jpn., 9, 205-210, doi:10.1007/s10310-003-0074-7, 2004.

Khan, M. N. I., Suwa, R., and Hagihara, A.: Allometric relationships for estimating the aboveground phytomass and leaf area of mangrove Kandelia candel (L.) Druce trees in the Manko Wetland, Okinawa Island, Japan, Trees, 19, 266-272, doi:10.1007/s00468-004-0377-0, 2005.

Khan, M. N. I., Suwa, R., and Hagihara, A.: Carbon and nitrogen pools in a mangrove stand of Kandelia obovata (S., L.) Yong: vertical distribution in the soil-vegetation system, Wetl. Ecol. Manag., 15, 141-153, doi:10.1007/s11273-006-9020-8, 2007.

Khan, M. N. I., Suwa, R., and Hagihara, A.: Biomass and aboveground net primary production in a pioneer mangrove Kandelia obovata (S., L.) Yong at Manko Wetland, Okinawa Island, Japan, Wetl. Ecol. Manag., 17, 585-599, doi:10.1007/s11273009-9136-8, 2009.

Krause, G., Schories, D., Glaser, M., and Diele, K.: Spatial patterns of mangrove ecosystems: the Bragantinian mangroves of northern Brazil (Bragança, Pará), Ecotropica, 7, 93-107, 2001.

Krauss, K. W., Lovelock, C. E., McKee, K. L., López-Hoffman, L., Ewe, S. M., and Sousa, W. P.: Environmental drivers in mangrove establishment and early development: a review, Aquat. Bot., 89, 105-127, doi:10.1016/j.aquabot.2007.12.014, 2008.

Kristensen, E., Bouillon, S., Dittmar, T., and Marchand, C.: Organic carbon dynamics in mangrove ecosystems: a review, Aquat. Bot., 89, 201-219, doi:10.1016/j.aquabot.2007.12.005, 2008.

Kubota, Y.: Spatial pattern and regeneration dynamics in a temperate Abies-Tsuga forest in southwestern Japan, J. For. Res.-Jpn., 11, 191-201, doi:10.1007/s10310-006-0205-z, 2006.

Law, R., Illian, J., Burslem, D., Gratzer, G., Gunatilleke, C., and Gunatilleke, I.: Ecological information from spatial patterns of plants: insights from point process theory, J. Ecol., 97, 616-628, doi:10.1111/j.1365-2745.2009.01510.x, 2009.

Lee, S. Y.: Litter production and turnover of the mangrove Kandelia candel (L.) druce in a Hong Kong tidal shrimp pond, Estuar.
Coast. Shelf S., 29, 75-87, 1989.

Liao, W. B., Lan, C. Y., Zan, Q. J., Wong, Y. S., and Tam, N. F. Y.: Growth dynamics and self-thinning of the dominant populations in the mangrove community, Acta. Bot. Sin., 46, 522-532, 2004.

Lonsdale, W. M.: The self-thinning rule: dead or alive?, Ecology, 71, 1373-1388, doi:10.2307/1938275, 1990.

Machiwa, F. and Hallberg, R. O.: An empirical model of the fate of organic carbon in a mangrove forest partly affected by anthropogenic activity, Ecol. Model., 147, 69-83, doi:10.1016/S03043800(01)00407-0, 2002.

Mahdi, A. and Law, R.: On the spatial organization of plant species in a limestone grassland community, J. Ecol., 75, 459-476, 1987.

Manabe, T., Nishimura, N., Miura, M., and Yamamoto, S.: Population structure and spatial patterns for trees in a temperate oldgrowth evergreen broad-leaved forest in Japan, Plant Ecol., 151, 181-197, doi:10.1023/A:1026512404110, 2000.

McKee, K. L.: Seedling recruitment patterns in a Belizean mangrove forest: effects of establishment ability and physico-chemical factors, Oecologia, 101, 448-460, doi:10.1007/BF00329423, 1995.

Mumby, P. J., Edwards, A. J., Arias-González, J. E., Lindeman, K. C., Blackwell, P. G., Gall, A., Gorczynska, M. I., Harborne, A. R., Pescod, C. L., Renken, H., Wabnitz, C. C. C., and Llewellyn, G.: Mangroves enhance the biomass of coral reef fish communities in the Caribbean, Nature, 427, 533-536, doi:10.1038/nature02286, 2004.

Ogawa, K.: Time trajectories of mass and density in a Chamaecyparis obtusa seedling population, Forest Ecol. Manag., 142, 291-296, doi:10.1016/S0378-1127(00)00358-3, 2001.

Ogawa, K.: Time-trajectory of mean phytomass and density during a course of self-thinning in a sugi (Cryptomeria japonica D. Don) plantation, Forest Ecol. Manag., 214, 104-110, doi:10.1016/j.foreco.2005.03.067, 2005.

Ogawa, K. and Hagihara, A.: Self-thinning and size variation in a sugi (Cryptomeria japonica D. Don) plantation, Forest Ecol Manag., 174, 413-421, doi:10.1016/S0378-1127(02)00062-2, 2003.

Osawa, A. and Allen, R. B.: Allometric theory explains selfthinning relationships of mountain beech and red pine, Ecology, 74, 1020-1032, doi:10.2307/1940472, 1993.

Osunkoya, O. O. and Greese, R.: Population structure, spatial pattern and seedling establishment of the grey mangrove, Avicennia marina, var. Australasia, in New Zealand, Aust. J. Bot., 45, 707 725, doi:10.1071/BT96070, 1997.

Piou, C., Feller, I. C., Berger, U., and Chi, F.: Zonation patterns of belizean offshore mangrove forests 41 years after a catastrophic hurricane, Biotropica, 38, 365-374, doi:10.1111/j.17447429.2006.00156.x, 2006.

Pujol, G., Iooss, B., and Janon, A.: Sensitivity: Sensitivity Analysis. R package version 1.6. http://CRAN.R-project.org/package= sensitivity, 2012.

R Development Core Team: R: A language and environment for statistical computing. R Foundation for Statistical Computing, Vienna, Austria, ISBN 3-900051-07-0, http://www.R-project.org/, 2011.

Rabinowitz, D.: Early growth of mangrove seedlings in Panama, and an hypothesis concerning the relationship of dispersal and zonation, J. Biogeogr., 5, 113-133, 1978. 
Ripley, B. D.: Test of randomness for spatial point patterns, J. Roy. Stat. Soc. B., 41, 368-374, 1979.

Rönnbäck, P.: The ecological basis for economic value of seafood production supported by mangrove ecosystems, Ecol. Econ., 29, 235-252, doi:10.1016/S0921-8009(99)00016-6, 1999.

Salas, C., LeMay, V., Nunez, P., Pacheco, P., and Espinosa, A.: Spatial patterns in an old-growth Nothofagus obliqua forest in south-central Chile, Forest Ecol. Manag., 231, 38-46, doi:10.1016/j.foreco.2006.04.037, 2006.

Saloranta, T. M. and Andersen, T.: MyLake - a multi-year lake simulation model code suitable for uncertainty and sensitivity analysis simulations, Ecol. Model., 207, 45-60, doi:10.1016/j.ecolmodel.2007.03.018, 2007.

Saltelli, A., Tarantola, S., and Chan, K. P. S.: A quantitative modelindependent method for global sensitivity analysis of model output, Technometrics, 41, 39-56, doi:10.2307/1270993, 1999.

Saltelli, A., Chan, K., and Scott, E. M. (Eds.): Sensitivity Analysis, John Wiley \& Sons, Chichester, UK, 2000.

Sherman, R. E., Fahey, T. J., and Martinez, P.: Spatial patterns of biomass and aboveground net primary productivity in a mangrove ecosystem in the Dominican Republic, Ecosystems, 6, 384-398, doi:10.1007/s10021-002-0191-8, 2003.

Shinozaki, K. and Kira, T.: Intraspecific competition among higher plants. VII. Logistic theory of the C-D effect, Journal of the Institute of Polytechnics, Osaka City University, 7, 35-72, 1956.

Shinozaki, K. and Kira, T.: The C-D rule, its theory and practical uses. (Intraspecific competition among higher plants X.), Journal of Biology Osaka City University, 12, 69-82, 1961.

Shugart, H. H.: A Theory of Forest Dynamics: The Ecological Implications of Forest Succession Models, Springer-Verlag, New York, 1984.

Silvertown, J. W. and Charlesworth, D. (Eds.): Introduction to plant population biology, Blackwell Science Ltd., Oxford, UK, 2001.

Silvertown, J. W. and Doust, J. L. (Eds.): Introduction to plant population biology, Blackwell Science Ltd., Oxford, UK, 1993.

SimLab: Version 2.2. Simulation Environment for Uncertainty and Sensitivity Analysis, developed by the Joint Research Centre of the European Commission. http://simlab.jrc.ec.europa.eu/, 2011

Souza, A. F. and Martins, F. R.: Population structure and dynamics of a neotropical palm in fire-impacted fragments of the Brazilian Atlantic Forest, Biodivers. Conserv., 13, 1611-1632, doi:10.1023/B:BIOC.0000029326.44647.7f, 2004.

Stoyan, D. and Penttinen, A.: Recent Applications of Point Process Methods in Forestry Statistics, Stat. Sci., 15, 61-78, doi:10.1214/ss/1009212674, 2000.

Stoyan, D. and Stoyan, H. (Eds.): Fractals, random shapes, and point fields: methods of geometrical statistics. Chichester, John Wiley \& Sons, 1994.
Suwa, R., Khan, M. N. I., and Hagihara, A.: Canopy photosynthesis, canopy respiration and surplus production in a subtropical mangrove Kandelia candel forest, Okinawa Island, Japan, Mar. Ecol.-Prog. Ser., 320, 131-139, doi:10.3354/meps320131, 2006.

Thibodeau, F. R. and Nickerson, N. H.: Differential oxidation of mangrove substrate by Avicennia germinans and Rhizophora mangle, Am. J. Bot., 73, 512-516, 1986.

Thompson, S. K.: Sampling. John Wiley \& Sons, Inc., New York, 1992.

Tüffers, A. V., Naidoo, G., and Willert, D. J. V.: The contribution of leaf angle to photoprotection in the mangroves Avicennia marina (Forssk.) Vierh. and Bruguiera gymnorrhiza (L.) Lam. under field conditions in South Africa, Flora, 194, 267-275, 1999.

Turkington, R. and Harper, J. L.: The growth, distribution and neighbour relationships of Trifolium repens in a permanent pasture. I Ordination, pattern and contact, J. Ecol., 67, 201-218, 1979.

Weiner, J. and Whigham, D. F.: Size variability and self-thinning in wild-rice (Zizania aquatica), Am. J. Bot., 75, 445-448, 1988.

Weller, D. E.: A re-evaluation of the $-3 / 2$ power rule of plant selfthinning, Ecol. Monogr., 57, 23-43, 1987.

Wilson, R. J., Thomas, C. D., Fox, R., Roy, D. B., and Kunin, W. E.: Spatial patterns in species distributions reveal biodiversity change, Nature, 432, 393-396, doi:10.1038/nature03031, 2004.

Xue, L. and Hagihara, A.: Growth analysis on the C-D effect in selfthinning Masson pine (Pinus massoniana) stands, Forest Ecol. Manag., 165, 249-256, doi:10.1016/S0378-1127(01)00622-3, 2002.

Xue, L. and Hagihara, A.: Growth analysis of the competitiondensity effect in non-self-thinning Populus deltoids and Populus $\times$ euramericana plantations, J. For. Res-Jpn., 13, 241-248, doi:10.1007/s10310-008-0070-z, 2008.

Xue, L., Ogawa, K., Hagihara, A., Liang, S., and Bai, J.: Selfthinning exponents based on the allometric model in Chinese pine (Pinus tabulaeformis Carr.) and Prince Rupprecht's larch (Larix principis-rupprechtii Mayr) stands, Forest Ecol. Manag., 117, 87-93, doi:10.1016/S0378-1127(98)00472-1, 1999.

Yamada, T. and Suzuki, E.: Changes in spatial distribution during the life history of a tropical tree, Scaphium macropodum (Sterculiaceae) in Borneo, J. Plant. Res., 110, 179-186, doi:10.1007/BF02509306, 1997.

Yoda, K., Kira, T., Ogawa, H., and Hozumi, K.: Self-thinning in overcrowded pure stands under cultivated and natural conditions. (Intraspecific competition among higher plants XI.), Journal of Biology Osaka City University, 14, 107-129, 1963.

Zeide, B.: Tolerance and self-tolerance of trees, Forest Ecol. Manag., 13, 149-166, doi:10.1016/0378-1127(85)90031-3, 1985. 